\title{
A Different Kind of Rigor: \\ What Climate Scientists Can Learn From Emergency Room Doctors ${ }^{1}$
}

\author{
Kent A. Peacock \\ Department of Philosophy, University of Lethbridge
}

\begin{abstract}
James Hansen and others have argued that climate scientists are often reluctant to speak out about extreme outcomes of anthropogenic carbonization. According to Hansen, such reticence lessens the chance of effective responses to these threats. With the collapse of the West Antarctic Ice Sheet (WAIS) as a case study, reasons for scientific reticence are reviewed. The challenges faced by scientists in finding the right balance between reticence and speaking out are both ethical and methodological. Scientists need a framework within which to find this balance. Such a framework can be found in the long-established practices of professional ethics.
\end{abstract}

${ }^{1}$ This paper is forthcoming in Ethics, Policy, and Environment. (The paper was accepted on June 26, 2017.) 


\section{Introduction}

Climate scientists are frequently accused of alarmism, but in fact there is evidence that scientists often exhibit what James Hansen has called reticence — an unwillingness to err on the side of predicting extreme outcomes or recommending strong action to prevent those outcomes (Hansen, 2007; Risbey, 2008). Recently, Kevin Anderson claimed that many climate scientists are "ultimately choosing to censor their own research" - research which shows that the widelytouted target of limiting global warming to a $2{ }^{\circ} \mathrm{C}$ "guardrail" cannot possibly be met without a far more drastic restructuring of humanity's means of generating energy than is politically palatable today (Anderson, 2015). Brysse et al. document a systematic tendency among scientists to "err on the side of least drama" when considering the possible effect of global warming, and suggest that such caution may be part of the culture of science (Brysse, Oreskes, O'Reilly, \& Oppenheimer, 2013).

Despite the imminent risks of global warming, many scientists are conflicted about their obligation to inform the public of possible risks versus their perceived imperative to not publish a mistake, and some climate scientists have argued that it is not the business of research scientists to comment on policy (Edwards, 2013). The urgency of the climate crisis (Hansen et al., 2013) is such that climate scientists need a clear ethical and methodological framework to guide their actions at this critical time. This paper will review some preliminaries, and then argue that elements of such a framework can be found in the long-standing principles and practices of professional ethics. 


\section{Case Study: WAIS, the Restless Giant}

I will cite the threat of ice sheet collapse as a case study, because it has been specifically mentioned by Hansen and others (Hansen, 2007; Risbey, 2008; Brysse et al. 2013) as a critically important example of a possible outcome of global warming about which some scientists have arguably exhibited undue reticence, and because recent research in glaciology supports concern about the urgency of this problem (Favier et al., 2014; Greenbaum et al., 2015; Joughin \& Alley, 2011; Joughin, Smith, \& Brooke, 2014; Pollard, DeConto, \& Alley, 2015; Rignot, 2014, DeConto \& Pollard, 2016).

Paleoclimate evidence shows that sea levels during some earlier interglacials were several metres higher than they are now, even though temperatures were not much higher than at present. Most of that extra interglacial water can only have come from the Greenland Ice Sheet (GIS) or the West Antarctic Ice Sheet (WAIS) (Hansen, Sato, Russell, \& Pushker, 2013). The stability of WAIS is a matter of particular concern. It is not an ice sheet draped over a land mass (like much of GIS) but rather a grounded marine ice sheet or dome, a vast lens of ice packed into an abyssal trench in the sea floor and held in place by the colossal weight of its "ice over flotation." Over half of the ice in WAIS is concentrated in the Bentley Trench, which goes down to $2500 \mathrm{~m}$ below sea level. The Trench is ringed by mountains and islands, with major outflow glaciers and ice streams connecting it to the sea. Glaciologists have long been aware that grounded marine ice sheets such as WAIS are inherently unstable and possibly subject to rapid disintegration (Weertman, 1974; Hughes, 1977; Mercer, 1978). WAIS in particular may be on a hair trigger, in part because of its relatively low ice over flotation compared to the major grounded ice sheets in East Antarctica. There is increasing evidence that portions of the Eastern 
Antarctic Ice Sheet (EAIS) (Greenbaum et al., 2015; Pollard et al., 2015) will ultimately be susceptible to disintegration or even rapid collapse as well.

The breakdown of a grounded ice sheet is presumably initiated by heat transport from warming ocean currents, but once a calving face has worked its way back into the interior basin of a marine ice sheet, rapid collapse may be inevitable for essentially mechanical reasons. As T. Hughes warned,

... a relatively minor climatic fluctuation along the ice shelf calving barrier can unleash glacial dynamic processes independent of climate that cause calving bays to remorselessly carve out the living heart of a marine ice sheet (Hughes, 1977, p. 43). In 1978, J. Mercer (1978), a scientist who was arguably not guilty of reticence, warned of the risk of catastrophic collapse of WAIS should $\mathrm{CO}_{2}$ concentrations be allowed to rise unchecked: If the $\mathrm{CO}_{2}$ greenhouse effect is magnified at high latitudes, as now seems likely, deglaciation of West Antarctica would probably be the first disastrous result of continued fossil fuel consumption (Mercer, 1978, p. 325).

Events in subsequent years have confirmed many of Mercer's specific predictions (such as his warning that the ice shelves on the Antarctic Peninsula could collapse), and some recent studies show that under current conditions the ultimate disintegration of WAIS over a period of no more than a few centuries may be virtually inevitable (Joughin et al., 2014; Rignot, 2014). However, it still remains unclear how long this process could take. There is a genuine possibility, however remote, that the whole contents of the Bentley Trench could shatter in a matter of weeks or months, raising global mean sea level by $3 \mathrm{~m}$ or more almost immediately. The South Asian tsunami of 2004 would pale in comparison to such a catastrophe, which would be both global in extent and irreversible over a multi-millennium time-scale. 
Ice sheet dynamics are complex and highly non-linear, and thus difficult to model or analyse with precision (Vaughn \& Arthern, 2007). The IPCC's most recent predictions of sealevel rise in Assessment Report 5 (AR5) did not take explicit account of dynamic ice sheet processes that could lead to rapid collapse (IPCC 2014, p. 16; Rahmstorf, 2013). Generally, paleoclimate studies suggest that ice masses can collapse much more rapidly than allowed for by the models of ice sheet dynamics that were available to the authors of AR5. Because of this conflict between modelling and paleoclimate data it did not seem possible to make sufficiently confident predictions about the possible future behavior of the ice caps as a function of various emission scenarios. Recent models of ice sheet behavior come closer to replicating the potential for rapid collapse indicated by paleoclimate, because they take into account highly non-linear mechanisms (particularly ice cliff instability and hydrofracturing) that were not included in earlier modelling (DeConto \& Pollard, 2016). Finally, some scientifically-informed reporting on the risk of marine ice sheet collapse is beginning to appear outside the professional literature (Goodell, 2017; Betz, 2017). But it is still not clear that an awareness of the risk of ice sheet collapse has entered the broad public discourse on climate, especially at the level of decisionmaking.

It may be that there is no significant risk of a collapse of WAIS until global mean temperatures get well above the nominal $2^{\circ} \mathrm{C}$ (above pre-industrial levels) that is currently accepted by international agreements as the threshold below which the risk of irreversible tipping points is deemed politically acceptable (UNFCCC, 2015). However, there can be no guarantee that WAIS will be miraculously protected from the same mechanisms that destroyed other marine ice sheets in the past. (See Hansen et al. 2016 for a critique of the adequacy of the $2^{\circ} \mathrm{C}$ 
guardrail.) Even if the probability of an imminent collapse of WAIS is low, this is surely a case where scientists should not choose to "err on the side of least drama" (Brysse et al., 2013).

\section{The Dilemma}

There is no question that many scientists and others who heed the science have indeed chosen to speak out about the dangers of anthropogenic carbonization, sometimes at significant personal cost (Oreskes \& Conway, 2010; Powell, 2011; Martin, 2014). Michael Mann, one of the authors of the "hockey stick" paper (Mann, Bradley, \& Hughes, 1998), states that he was at first convinced that any attempt to take a position on climate policy would "compromise the authority of my science," but he eventually came to feel that

there is nothing more noble than striving to communicate, in terms that are simultaneously accurate and accessible, the societal implications of our scientific knowledge. (Mann 2012, p. 253)

If scientists of good will are still unduly reticent (as claimed by Hansen, Anderson, and Brysse et al.), it is to an important extent because they are not sure when the need to speak out overrides the need to strive for the highest level of scientific certainty before claiming any sort of result. (There can also be non-scientific or even non-cognitive reasons for reticence, outlined below.) The problem is therefore methodological as well as ethical. If it were possible for glaciologists to produce a timetable for the collapse of WAIS as a function of various emission scenarios then

they could warn of these risks with much more confidence, and likely most would be inclined to do so. However, the precise timing of a climatic catastrophe such as the collapse of a major ice sheet is inherently difficult or impossible to establish. This is partially because such catastrophes may be triggered by the amplification (via various feedbacks) of small, unpredictable 
fluctuations. In this respect there is a similarity to the challenge of predicting earthquakes: it may be much easier to identify the risk of a major quake in a certain region than to estimate its probability within a given time-frame (especially a relatively short time-frame).

The difficulty with making predictions of climate catastrophes also arises to an important extent because the possible outcomes we are concerned with (such as the collapse of WAIS, an ice-free Arctic, or widespread oceanic anoxia) are unprecedented in human experience. One of the few things that can be said with real confidence is that the probability of such events must increase with time, given our present understanding of the physics behind them and the paleoclimate record. (In this respect there is a disanalogy with earthquakes, the probability of which is roughly constant over a long enough time scale.) However, predicting ice sheet collapse is not like predicting heart attacks or trucking accidents, for which there are wellestablished statistics. How, then, are scientists to provide the advice that is so badly needed? And what sort of advice should they provide?

\section{Some Principles of Disaster Prevention}

Without attempting to present a complete theory of disaster prevention, I will point to three principles that point to the kind of advice needed in the present crisis.

First, a "weak signal" is often the only warning we may have of an impending disaster (Gerstein \& Ellsberg, 2008). If the water suddenly recedes from a beach, run! - don't wait for confirmation or permission. Action should be triggered by the reception of a signal that has a reasonable probability of being a sign of an impending catastrophe, even if in isolation from background information it looks like nothing more than an unremarkable oddity. Some of the earliest warnings about anthropogenic carbonization came thirty or more years ago (Mercer 
1978; Weart, 2014), when it was much more difficult to separate the global warming signal from the noise than it is now; these early warnings have proven to be accurate.

The second relevant principle of disaster prevention is not to attempt the usually impossible task of predicting the small fluctuations that can trigger a catastrophe, but rather to determine the range of parameters outside of which a complex system will be sensitive to small fluctuations. Machines such as automobiles, if well designed and properly built, have a range of parameters within which they are very robust to perturbation, whereas outside that range even the best-designed machine may fail if subject to a perturbation that it could have easily withstood inside its envelope of safety. Similarly, ecological and climatic systems tend to be selfstabilizing within certain ranges (partially due to a variety of feedbacks) but unstable outside those ranges. For example, as Hughes warned, once a marine ice sheet gets into a sufficiently vulnerable state, a local fluctuation could trigger a chain of catastrophic events with global consequences. The goal, therefore, is not to attempt to predict each conceivable fluctuation (which is impossible anyway), but to predict the range of parameters (such as ocean current temperatures or the position of a glacial grounding line) within which fluctuations become dangerous. That's why I should buy new tires for my car when the old ones wear past a certain point, and that's why one of the most important goals of climate science must be to identify the range of crucial parameters outside of which small fluctuations could trigger catastrophic outcomes. Even if it is virtually impossible to predict the particular "black swan" (Taleb, 2010) fluctuation that triggers a catastrophe, it is often possible to predict the range of controlling parameters outside of which such fluctuations are likely to be important.

Finally, there is the old adage, "An ounce of prevention is worth a pound of cure" (Brysse et al., 2013). If the ice dome in the Bentley Trench starts to blow apart, there is no conceivable 
technology outside the realm of science fiction that could stop it. But we still do not know that it will not be possible to prevent this catastrophe with a modest expenditure of a few hundred billion dollars on alternative energy technologies, if we start working on it soon enough.

\section{Reasons (Good and Bad) for Reticence}

As Hansen remarks, ...'scientific reticence'...hinders communication with the public about dangers of global warming... Caution, if not reticence, has its merits. However, in a case such as ice sheet instability and sea level rise, there is a danger in excessive caution. We may rue reticence, if it serves to lock in future disasters (2007).

It is worth reviewing some of the reasons why scientists may voluntarily choose to be reticent:

1. A good reason: In science it is very hard to be right, very easy to be wrong. Scientists are understandably reluctant to publish a result or prediction unless they are virtually certain about it, or at least about the level of uncertainty they can attach to it.

2. A not-so-good reason: stubborn pride. A notable historical example is the eminent $19^{\text {th }}$ century mathematician Karl Friedrich Gauss. His personal motto was pauca sed pura, "few but ripe" (Bell, 1937). Gauss would not publish anything until it was polished to perfection, with the result that some of his important discoveries (such as non-Euclidean geometry) were scooped by younger and slightly less cautious mathematicians. One would think that with the relentless pressure to publish faced by most scientists these days, Gaussian reticence would be rare. However, it might be used as an excuse to withhold results that could be controversial or disconcerting. 
3. A regrettable reason: scientists may reasonably fear that they would lose funding if they pursue unorthodox topics or extreme case scenarios (J. E. Hansen, 2007). Granting agencies have probably always tended to be risk-averse, but, as Lee Smolin points out (Smolin, 2006), it is increasingly difficult to get support for innovative research in today's climate of budgetary restraint. There is, therefore, an incentive for scientists working in all fields (not only climate) to be cautious - even when their work does not threaten the continued profitability of a large sector of industry.

4. A very regrettable reason: scientists can become subject to personal attacks (Mann, 2012; Powell, 2011) or risk the loss of their livelihoods; therefore some, quite understandably, may choose to keep their heads low.

5. Scientists working for government agencies are often prohibited from discussing their research or its policy implications, on pain of job loss or worse (Schindler, 2017).

6. Fear of disapproval from colleagues, supervisors, or the scientific community (Brysse et al., 2013) is a key reason for scientific reticence as well, but this factor cuts both ways. Appropriate caution may increase a scientist's reputation for reliability, but there are cases where advances have been hindered when a scientist bowed to the prejudices of his or her supervisor or other critics (Lindley, 2007, Ch. 8).

Climate scientists may also be unconsciously hesitant to say what they know because of possible "seepage" into professional discourse of the often-poisonous atmosphere of climate science denialism (Lewandkowsky, Oreskes, Risbey, \& Newell, 2015; Biddle \& Leuschner, 2015).

Finally, there is the methodological challenge to which this paper draws particular attention: Scientists lack clear guidelines for the relatively rare cases when pure scientific 
research points to challenges of urgent public importance which may require a response under uncertainty.

The "inconvenient truth" is that there are some possible outcomes (such as the collapse of WAIS) that are too important and too urgent to be reticent about, despite the scientific uncertainties surrounding them. Scientists need an ethical and methodological framework that coheres with the scientific ethos but which could help them find the right balance between reticence and speaking out. Oreskes (2013) has argued that scientists should be treated as sentinels, and Torcello (2011) argues that scientists have an obligation to inform public discourse in an unbiased way on the basis of Rawlsian ideals of public reason. The approach I explore here is in the spirit of these suggestions but draws on the long-established model of professional ethics. (R. Chadwick, 2005, has also argued, but from a different philosophical viewpoint, that scientists could be guided by the model of professional ethics.) I claim that when it comes to possible outcomes that are both immediate and catastrophic, climate scientists should think more like emergency room doctors than medical researchers. In the following I will explain what this would mean.

\section{Main Points of Professional Ethics}

Although the legal details vary from one jurisdiction to another, certain key features of the learned professions are common throughout the industrialized world and have their basis in centuries of practice. Notably, the legally constituted learned professions such as medicine and engineering are self-regulating, which means that it is professionals themselves who largely or entirely control accreditation and discipline. The ancient rhetorical question — quis custodiet ipsos custodes? - expresses implicitly the uncomfortable fact that in the last analysis there is no 
one to guard the guardians from impropriety but the guardians themselves; this is a major reason why codes of personal ethics must be integral to professional law.

In the following I will refer mainly to engineering and medicine, but several other professions are constituted in ways very similar to that described here.

The aspects of professionalism most relevant to our present discussion are these:

1. Professionals have a duty to decide: life and death decisions must be made in real time, often under conditions of uncertainty.

2. Medical doctors and engineers have a duty to innovate if a problem demands it, but they must do this in a conservative way because experimentation is not allowed.

3. Professional decisions are often required in cases where there is no algorithm. Such cases require judgement, an ability to weigh the pros and cons of a complex problem and act decisively and creatively.

4. Professionals must avoid negligence. There is a higher onus placed upon them than upon members of the general public to go out of their way in their areas of competency to do those things would be right and necessary according to their professional judgement.

5. Members of the learned professions have a duty to report (whistle-blow) and a duty to inform the public. Under certain circumstances, the duty to report, which is legislated, over-ride duties to self, the client, or any vested interests.

6. Professionals have a duty to self-educate, to maintain and expand their competence as required by the demands of their practice.

7. It is presumed that professionals enjoy epistemic privilege within their fields of practice. This justifies the fact that practitioners are given certain clearly delineated legal powers that other citizens do not have. 
8. Professionals must act in a way that is entirely impartial and free from conflict of interest.

9. Public welfare is given highest priority, in a way that is guided by the precautionary principle (discussed below).

I will now explain some of these points in more detail; see also (American College of Emergency Physicians, 2008; American Society of Civil Engineers (ASCE), 2006; Andrews \& Kemper, 1992; Engineering Council \& Royal Academy of Engineering, 2014; Peacock \& Shepherd, 1998).

\subsection{Duty to Decide}

Consider what emergency room physicians have to do: Their training has a basis in centuries of medical practice and the best science available, but they do not have the luxury of investigating a problem for an indefinite length of time. The right decisions have to be made, often very quickly, with no room for trial-and-error. The duty to decide therefore implies not a lessening of intellectual rigor but a different kind of rigor than that cultivated in pure research. (More on this below.)

\subsection{Duty to Innovate - Conservatively}

Experienced physicians or engineers are usually presented with problems that they have seen many times before. However, occasionally they will be presented with a novel challenge, and it is above all else the expectation that they can cope with novelty that justifies their high economic and social status. Thus, like research scientists, they work at the frontiers of knowledge and expertise. Unlike research scientists, though, they cannot indulge in experimentation. (Medical research may be combined with treatment, though only under very specific constraints.) Engineers and physicians often engage in pure research, but when they are 
working on a particular case, with lives at stake, they must get it right the first time. Those who contemplate geoengineering (Broecker \& Kunzig, 2008; Keith, 2013) need to keep these principles in mind. It would not be surprising if geoengineering itself eventually were to become a recognized discipline within the engineering profession, as societies scramble to respond to climate change.

\subsection{The Essential Role of Good Judgement}

Professionals are trained in the application of a plethora of algorithms, but they must occasionally solve a problem, in low finite time, without the benefit of a full algorithm for that particular case. Such cases require judgement in much the sense indicated by Aristotle (Nichomachean Ethics, in, e.g., McKeon 1941). Good professional judgement is in the last analysis non-algorithmic and has an essentially aesthetic component. Thoughtful people sometimes find this troubling, because they feel that medicine and engineering are the last places where one should rely on something that superficially looks like mere guesswork. In fact, the kind of non-algorithmic judgement I speak of here can only be exercised by those with appropriate experience and training, and the need for it can never be entirely obviated regardless of what procedures, protocols, formulas, algorithms, or guidelines may be put in place.

\subsection{Avoidance of Negligence}

Professionals can face both civil and criminal penalties not only if they do the wrong thing, but if they fail to do the right thing. However, the definition of negligence that is given in typical professional codes is frustratingly non-specific. For instance, the engineering code for the Province of Ontario merely states that professional negligence is "an act or an omission in the carrying out of the work of a practitioner that constitutes a failure to maintain the standards that a 
reasonable and prudent practitioner would maintain in the circumstances" ("Definition of Professional Misconduct; Ontario Regulation 538/84, Sect. 86,” 1990).

Thus, what would constitute negligence in a particular case is to an important extent determined by case law, if there is precedent for the case at hand, but ultimately is a matter of the good judgement of the practitioner. It is not possible to prescribe in advance, fully and precisely, a list of which acts would constitute negligence and which would not. Engineers are liable if they get it wrong even though it is not always possible to tell them precisely what would constitute negligence in any particular case. Could it be negligent to not speak out more forcefully and publicly about the possible dangers of sudden WAIS collapse? Only glaciologists and other relevantly qualified scientists can answer that question, but there is no formula to tell them how to answer.

\subsection{Duty to Report}

Professionals are cautioned to not blow the whistle unless they have exhausted all normal channels of command and communication. However, in extremis their duty to report over-rides all other considerations, including loyalty to their colleagues, employers, and clients — and their own job security. This was explained bluntly by the Professional Engineers of Ontario:

Engineers must act out of a sense of duty, with full knowledge of the effect of their actions, and accept responsibility for their judgment [in a way that is] open, personal, [and] conducted with the interest of the public in mind... [This] obviously requires that engineers put their names on the action and sometimes their jobs on the line (Anon., 2010).

What applies to professional engineers could be taken to apply to tenured academics as well, though in their case the duty to report is implicit rather than being explicitly enshrined in law. 
Noam Chomsky famously stated that "it is the responsibility of intellectuals to speak the truth and to expose lies" (Chomsky, 1967). Some intellectuals, including some scientists, are fortunate enough to enjoy the privilege of academic tenure, an institution which is intended to protect freedom of inquiry, expression, and criticism for the greater benefit of humanity. Those of us with academic tenure therefore may well feel that we have a particularly strong obligation to blow whistles when the evidence demands it.

\subsection{Knowing One's Limitations}

Some will point out that I've forgotten to mention one important component of professional ethics: practitioners have a duty to know the limits of their own competence and to not attempt to operate outside those limits. Such a duty certainly does exist. However, the main problem addressed in this paper is the fact that some scientists are reluctant to speak out regarding matters on which they are, indeed, competent. If one's scientific expertise about (say) ice sheet dynamics points to the need to comment on a matter such as (say) energy policy, then one may have a duty to self-educate so as to be able to speak with at least minimal competence in that area, or else cite or seek collaboration with other professionals who do have the requisite competencies.

\subsection{Epistemic Privilege}

The legal authority of the learned professions is underpinned by their epistemic privilege, which means that professionals are presumed to have access to knowledge that is not available to other members of society. Suppose my friend Bloggs is walking along intently texting on his smart phone and does not notice that he is about to step off the curb into fast-moving traffic. I'm standing close by. There are many things about Bloggs that I am in no position to comment on unless invited by him to do so. But I do happen to know one urgent matter of great importance 
to him, a matter of which he is unaware. My epistemic privilege, coupled with even the most minimal notions of ethics, both entitles and requires me to call out a warning to him or even to physically restrain him before he gets run over. Similarly, while there are many matters on which climate scientists cannot be expected to be competent to provide advice, they do have very well-founded knowledge about certain matters of great urgency which most people are not in a position to understand. From the point of view of professional ethics, it is entirely appropriate, and indeed it may be required, for them to speak out - even if there is an appreciable chance that they are wrong.

There is, of course, no logical path from the bare fact that Bloggs is about to get run over to the normative claim that I ought to warn him. It has been recognized by philosophers from Hume onward (Hume, 1751) that one cannot get an 'ought' from an 'is'. That is why my knowledge of Bloggs' problem needs to be coupled with some notions, however minimal, of ethical obligation. In this paper we need not explore the deep question of where such notions could come from, although it is worth noting that in codes of professional ethics they typically cash out in deontic form; that is, they are expressed as duties and expectations even if their philosophical basis might lie elsewhere.

\subsection{Freedom from Conflict of Interest}

Professionals are in a conflict of interest, or at least a perceived or potential conflict of interest, if they allow themselves to be caught in a situation in which it is possible for the objectivity of their professional judgement to be subverted by personal gain, advancement, or favouritism. The very term "conflict of interest" suggests that one is serving more than one master. Professional guidelines and codes invariably contain provisions to forestall conflicts of interest. For instance, engineers and medical doctors are generally not permitted to provide 
expert testimony in a court case for a contingent fee — that is, a fee that would depend upon the outcome of the case (American Medical Association (AMA), 2004; Bennet et al., 2012; International Board of Forensic Engineering Sciences (IBFES)).

A common denialist trope is that climate scientists exaggerate the risks of $\mathrm{CO}_{2}$ emissions in order to trump up more research grants, or perhaps to garner publicity, prestige, or career advancement. (See, e.g., Mann 2012, pp. 202-206.) One of the mechanisms that protect scientists from such charges is the peer review system, which, though arguably imperfect in ways we need not explore here, is designed to maintain high epistemic standards and to ensure that publication, granting, and promotion depend only upon scientific merit. Another key mechanism is the high value placed on independent replicability of claimed scientific results.

While any number of legal, procedural, or methodological mechanisms can be put in place to protect the public from professional conflict of interest, professionals understand (or should understand) that their stock in trade is their personal intellectual integrity; this is the case for research scientists as well as registered professionals such as doctors or engineers. Integrity is not only a matter of telling the truth when asked but also of speaking out when it is not ethically possible to do otherwise. What does it mean to "tell the truth"? The core of intellectual integrity in both the learned professions and research science is the presumption that judgements are advanced for cognitive reasons, not rhetorical reasons. A professional judgement could, of course, be in error, but it is based on the best efforts of a highly-trained person to get it right on the basis of evidence and reasoning; it is not a sales pitch.

\subsection{The Precautionary Principle}

The ancient Hippocratic oath enjoined physicians to "do no harm," but practitioners know that they must balance this with the imperative to take action when it would be 
unconscionable not to (Harris, 1995). Brysse et al. (2013) quote the highly apposite version of the Precautionary Principle given in the Rio Declaration of 1992:

Where there are threats of serious or irreversible damage, lack of full scientific certainty shall not be used as a reason for postponing cost-effective measures to prevent environmental degradation.

Nor should lack of full scientific certainty be an excuse for not speaking out about the risks of catastrophic events that do, in fact, have a reasonable probability of occurring.

One might ask why we could not use risk-benefit analysis rather than the seemingly less rigorous precautionary principle to plot the climate and energy policies that have the best chance of maximizing general utility. One advantage of the Precautionary Principle is that it explicitly shifts the burden of proof onto the parties who would advocate for the course of action that is likely to lead to the most damaging outcomes (Mann \& Toles 2016, p. 12). But risk-benefit analysis has significant ethical and methodological weaknesses as well. The ethical problem is that it can be difficult to carry out a risk-benefit analysis in a fair and impartial way, especially if the parties exposed to possible risks are not the same as the parties who may benefit from the course of action being analyzed (Shrader-Frechette, 1986). The methodological problem is that climate change outcomes are not the sorts of things that are readily amenable to risk-benefit analysis in the first place.

The latter point deserves some explanation. In order to carry out a meaningful riskbenefit analysis of a possible course of action, one needs to know three things: all possible outcomes of that course of action that could affect utility, the utilities or disutilities of each possible outcome, and the probabilities (in the sense of long-run frequency) of each possible outcome. Risk-benefit analysis can be useful, therefore, in assessing possible actions (such as 
construction projects) that either have been done many times before, or are built up in unproblematic ways out of actions that have been done many times before. Actuaries have compiled reliable statistics on the incidence of typical industrial accidents, for instance, so that the likely disutility of such accidents attendant upon a project can be readily calculated.

One of the major methodological challenges posed by possible outcomes such as the rapid collapse of WAIS is that we are trying to estimate the probability of an event that has not occurred within recorded human history. Paleoclimate data does provide some guidance about the conditions under which such events could occur and how rapidly they could occur, but for several obvious reasons it is not possible to estimate with any real confidence the probability that WAIS will collapse in, say, the next fifty years. All that can be said with any approach to certainty is that humanity is presently engineering the physical conditions (such as the disintegration of ice shelves and warming of deep ocean currents) which, as far as we know, will increasingly tend to favour the eventual collapse of grounded marine ice sheets.

It is also impossible to meaningfully predict the quantitative disutility of (say) a sudden three metre sea level rise caused by the collapse of a grounded ice sheet. Would it merely produce 100 million refugees and the overnight loss of most coastal cities and an appreciable portion of the world's agriculture, or would it trigger an escalating chain reaction of disasters that would lead to the complete collapse of technological civilization? (See World Bank 2007 and Hansen et al. 2016 for some analysis of the possible impact of multi-metre sea level rise.) All we can be sure of is that the consequences would be so bad that it is almost meaningless to assign a dollar value to them; as the popular saying has it, "we just don't want to go there." We do not need an exercise in spurious numerical precision to know that we want to place a very high priority on whatever it takes to move the planet away from the physical conditions that could 
precipitate the collapse of WAIS. And among other things this implies that scientists need to accept some intellectual risks and share, not only what they know, but what they strongly suspect to be relevant to this hugely important problem.

\subsection{Some Disanalogies between Research Science and the Learned Professions}

The analogies between research science and the learned professions are not perfect. A major distinction is that professionals such as engineers are hired to do a specific job of work or to solve a specific problem, often for a specific client or patient. Research science, on the other hand, is open-ended, exploratory, even when an area of research (such as, say, the molecular basis of cancer) is directed toward solving a particular class of problems. The client is the public in the broadest sense, under the working assumption that the expansion of knowledge is in the interest of the long-range welfare of the human species.

While there are admirable codes of scientific ethics (e.g., AGU, 2013a), scientific research is not a legally constituted profession such as medicine, law, or engineering, and its codes of ethics (explicit or implicit as they may be) are in general not legally enforceable. By contrast, the ethical codes for the learned professions are usually part of the laws governing those professions; an engineer is legally required to behave ethically, at least in respect to his or her professional work. Indeed, licensed professionals are in general required to accept a level of personal responsibility that would be supererogatory for non-professionals.

Furthermore, research scientists do not enjoy the kind of legal protection that engineers or doctors enjoy (at least in theory) if they should find it necessary to blow a whistle. This, of course, could be another reason why scientists may tend to be unduly reticent when the evidence would otherwise compel them to bring bad news. 
One possible objection to the views of this paper might be to claim that there is a "disconnect" between research science and the learned professions, since the latter fields seem to have more "direct, immediate implications on individuals' livelihoods" (as a referee put it) while pure science deals with matters which are both uncertain and remote.

To respond to this, it is essential to distinguish between the scale of a decision, and the type of a decision. It is perfectly correct that medicine and engineering usually seem to have more direct bearing on our day-to-day lives than planetary-scale ecological research. I am more likely to go to my doctor because I have a cough than because I seek advice on the survival of the species. But what counts is the methodology that the physician must use. Do I need cough syrup or radical surgery? These are the sorts of sometimes-momentous decisions under uncertainty that medical professionals routinely have to make. A prescription for cough syrup for one patient is more local than a prescription for a major change in energy policy, which could affect every person on the planet. But the type of reasoning is essentially the same - a scientifically well-founded decision must be made under uncertainty, within a limited time frame, and driven by an ethical imperative.

Also, let us not forget that doctors and engineers obviously often do give advice with long-term and wide-ranging impact. Doctors warn young people not to smoke, or they advise patients to alter their diets or get more exercise because of long-term benefits those changes will bring. Medical professionals may make decisions, such as whether or not to vaccinate a population or to approve a new chemotherapy, which can affect millions of people. Engineers often work on projects that have large implications for long-term public well-being, such as bridges, dams, or electricity distribution networks. There is no real disconnect between the types of problems that doctors and engineers solve and the challenge that a glaciologist faces when 
trying to decide when and how to speak out about the possible global risks of a major ice sheet collapse. It's just a question of scale, in terms of the number of people (patients) who may be affected or the spatial and temporal scale over which the decision may have its effects. The commonality, again, is the methodology of decision-making.

The medical example also underscores a key point that is implicit throughout this paper. Like medical doctors and engineers, scientists must not only diagnose a problem but prescribe possible solutions, or at least lend their competence to the formulation of such solutions. Policy cannot be left to policy-makers alone any more than medical advice could be left entirely to those without medical training.

Despite some important disanalogies, the learned professions offer an exemplar that climate and other scientists can voluntarily emulate when faced with the need to balance epistemic certainty with the need to warn the public about risks. Through many centuries of practice the professions have evolved a set of clear ethical standards based upon responsibilities to the patient, client, and society at large, and a methodology that (while difficult to formalize or quantify) constitutes a long-tested, pragmatic means of balancing the need for epistemic certainty with the need to act or speak out decisively.

\subsection{The Upshot}

From the duties to decide and to report, it follows that in cases (such as the possible collapse of WAIS) where action is demanded by the precautionary principle, scientists who wish to emulate the professions must eschew reticence. They must use their professional judgement to estimate risks and propose solutions even when reliable algorithms for doing those things do not exist. And they must do this utterly without special favour — though it is perhaps too much to expect that, being human, they will always be able to do it entirely without fear. 


\section{A Different Kind of Rigor}

I do not recommending a lessening of the standards of scientific rigor any more than I recommend that scientists allow their advocacy for a position held for non-scientific reasons to bias their science. Rather, I am arguing for a different kind of rigor — one that recognizes that the need for the highest possible epistemic certainty must sometimes be counterbalanced by the need for the best possible decisions to be made in finite time, with less-than-perfect resources of information. This is the rigor that professionals in fields such as medicine and engineering have been required to aim at for centuries, and it can be very difficult to achieve. It is far easier to withhold assent until one's result is confirmed to seven standard deviations. Indeed, it is reasonable to hold out for such near-Cartesian certainty in cases like the detection of the Higgs boson (Anthony, 2012). Presumably the immediate fate of civilization does not depend upon whether this elementary particle exists, and it is only useful as a building block of scientific knowledge if its properties are confirmed with the highest accuracy that experimental technique will allow. While many of the specifics of climate science, such as the claim that $\mathrm{CO}_{2}$ is a greenhouse gas, would be accepted by scientists as much more than 95\% certain (Borenstein, 2013), the IPCC allows for a certainty level as low as only $95 \%$ ("extremely likely") for their conclusion that "human influence has been the dominant cause of the observed warming since the mid-20th century" (IPCC, 2014). This is comparable to or exceeds the level of certainty with which medical practice must frequently content itself (see, e.g., Castillo, 2010).

The very notion of epistemic rigor has to have a different meaning when we discuss disaster prevention rather than the confirmation of scientific hypotheses. A full analysis of scientific uncertainty is beyond the scope of this paper. However, it is clear that the aim of 
climate science with respect to the future of WAIS is not to confirm that this ice sheet will definitely collapse under certain circumstances — we do not want to test that claim — but rather to show how to avoid the parameter regimes in which that outcome is probable. This implies that it will not always be possible to recommend preventative measures with absolute confidence that they will be relevant or effective. Uncertainty is our constant companion in real-life decision-making, and as Lewandowsky et al. argue (Lewandowsky, Risbey, Smithson, Newell, \& Hunter, 2014), it may be rational for uncertainty about high-risk outcomes to provide increased justification for pre-emptive action. While we may not be certain of the probability of an outcome such as the collapse of WAIS, we may be certain that it is an outcome we wish to avoid. Furthermore, if we aren't sure of the probability of such an outcome, there is a chance that it is higher than we currently estimate. Thus, if there is an appreciable possibility of that outcome, its uncertainty is all the more reason for striving to prevent it.

\section{The Challenge of Communication}

The major concern of this paper is whether or not to communicate a scientific result or its implications, not how to communicate it - how, that is, in the sense of finding effective techniques of communication and teaching. But the difficulty of communicating complex and uncertain scientific concepts to the public is likely yet another reason in itself for undue scientific reticence, and something must be said about it here.

This paper has focussed mostly on the need to communicate extreme risks such as the collapse of major ice sheets. Arguably this could increase the perception of climate scientists as alarmist. Well, what if one is an alarmist? It is irresponsible to cry "Fire!" in a crowded theatre if there is no fire; it is criminal to not call out a warning if there is (Torcello, 2017). However, 
this paper hardly means to suggest that scientists should only speak out in cases of extreme and immediate risk. Scientists should certainly be better prepared and trained than they often are to enter the public discourse around a range of topics. High risk issues are highlighted in this paper because those are the topics that are the most difficult on which to speak out. No one is going to send a scientist a death threat for discussing the merits of string theory. So scientists have the greatest need for clearer guidelines in the cases such as ice-sheet collapse where the challenges to speaking out are greatest.

S. H. Schneider made a now-classical argument for the need for his fellow climate scientists to communicate with the public:

[T]hose of you who turn away from attempts to communicate honestly and effectively in public because it is not familiar or comfortable, are simply leaving the task to others not all of whom will express your science in a way that you might approve of. (Schneider 1988, p. 115)

There is evidence that the task of communication is not hopeless (Kocher et al., 2017), and behavioral studies of public response to science communication (such as Poortinga et al., 2011) could be a valuable resource. However, one of the greatest barriers to climate science communication is the extreme politicization of much of the current discourse on climate and energy. In an interview on November 23, 2016, Robert Walker, an advisor to then-President elect Trump stated,

...some of the, at least, press statements coming out of those scientific investigations have more of a political feel than a scientific one. Look, I'm not a bench scientist. I'm a politician. I know politics when I see it. (CBC Radio) 
It is too easy to retort that Mr. Walker does not know science when he sees it. But there is a more subtle problem here. A scientific conclusion (such as a statement about the likelihood of ice sheet collapse) is advanced for scientific reasons. However, scientific conclusions about climate and energy often have policy implications, sometimes quite obvious, sometimes not so obvious. If medical tests show that I am prediabetic, it is a short step to appropriate advice about diet, exercise, or medication. But no responsible doctor would say that I was prediabetic merely because he or she thought that more exercise would be good for me. Similarly, the fact that certain findings in glaciology have policy implications does not mean that these findings were presented merely as rhetoric in order to advance those policies. However, it might look that way to those who do not understand how science works, or who are politically motivated to mistrust the scientists. As with medicine, so it is with earth science: if people don't like the advice, they are tempted to question the motives behind the diagnosis.

Another major barrier to communicating the risks of climate change is cognitive distancing, the tendency to downplay the importance of eventualities such as catastrophic sea level rise that we (sometimes mistakenly) believe to lie comfortably far in the future or to be someone else's problem. Socrates (Protagoras, 356c-e; in, e.g., Hamilton \& Cairns, 1961) likens this cognitive error to thinking that objects in the distance really are smaller than they are close by, and argues that our happiness depends upon learning to judge things by measurement, not appearances. There is no question that the urgent can pre-empt the important — if my house catches fire I can't devote any attention to global warming at that moment, even if the fire was caused by global warming. However, a major task for non-reticent scientists is to communicate an accurate sense of perspective and scale, to show how (for example) paleoclimate is immediately relevant to policy decisions that must be made in the near-term. One of the best 
ways to overcome cognitive distancing (which is not only a cognitive error but a kind of denial or defense mechanism in itself) may be to show that the situation is not hopeless, that there are scientifically possible solutions to at least some of the ecological challenges that humanity currently faces (Jacobson \& Delucchi, 2011).

In recent years a number of climate and earth scientists have taken a cue from Schneider and tried (in many cases very hard) to communicate the urgency of our present climate crisis to the public and policy-makers. (See, for instance, AGU 2013b.) Despite these efforts, no climate scientist of whom I am aware is satisfied that they are doing a good enough job of communication; see, for instance, recent remarks by the distinguished glaciologist E. Rignot (2015).

Science communication has a long history, going back at least as far as Galileo, who risked the rack to publish his highly accessible writings in the vernacular. One of the most notable instances of scientists attempting to communicate urgent warnings to the public was the Russell-Einstein Manifesto of 1955. The scientists who signed this document were speaking out about the dangers of nuclear conflagration. Many of them felt a deep sense of personal responsibility since their work had helped make nuclear weapons possible. Although the manifesto is about the risk of nuclear war, with one correction a key paragraph in it is a very accurate description of the climate crisis today:

Many warnings have been uttered by eminent men [and women] of science and by authorities in military strategy. None of them will say that the worst results are certain. What they do say is that these results are possible, and no one can be sure that they will not be realized. We have not yet found that the views of experts on this question depend in any degree upon their politics or prejudices. They depend only, so far as our researches 
have revealed, upon the extent of the particular expert's knowledge. We have found that the men [and women] who know most are the most gloomy. (Russell et al., 1955)

\section{A Long Tradition}

To summarize: Climatologists and other scientists who are troubled by a sense of responsibility would do well to voluntarily think of themselves as bound by ethical constraints similar to those that guide the learned professions such as engineering and medicine. The most relevant of these to the problem of reticence are the duty to decide, the duty to report, and the duty to inform. The duty to decide is the inescapable need for professionals to make concrete decisions or recommendations in finite time, often without what Hansen (2007) called "the comfort of waiting for incontrovertible confirmations." The duties to inform and report require professionals to bypass chains of command and speak out to the public in clearest terms about matters of public interest.

I do not advocate the formal professionalization of climate science, much less scientific research in general (although it would be desirable to have better means by which scientists could be legally protected when they find a need to speak out in ways that may threaten vested interests). There would be obvious practical impediments to the professionalization of research science, especially in the short time frame presented to us by the climate challenges we face today. More important, there probably will always be talented research scientists who are indifferent or blind to the human implications of their work; nevertheless, society may benefit from their insights, perhaps crucially. In the end, the most important qualifications for accreditation as a research scientist are and must remain ability and accomplishment in research. 
Therefore, it could be counterproductive to formally professionalize climate science, let alone scientific research in general.

The burden of this paper is to advocate that those scientists who are indeed troubled about the broader implications of their findings may find it helpful to train themselves to respond voluntarily like engineers or emergency room doctors in cases where there genuinely are reasonable grounds for a sense of urgency. The fact remains that presently scientists cannot (in general) be legally compelled to speak out to the extent that licensed professionals can. Hence, the recommendation given by this paper is conditional: if a research scientist wants to accept greater responsibility but is not sure how to square this with the need for scientific rigor, there does exist a long-established model that can be followed. Scientists who prefer to not speak out publicly should, however, be warned that, like the scientists and public officials in the L'Aquila case (Ropeik, 2012; Torcello, 2014), they could find themselves liable anyway if they fail to warn of risks that only they may have been able to accurately assess. As Ropeik (2012) explains, the seven scientists and officials were jailed not for failing to predict the earthquake that killed over 300 persons at L'Aquila, Italy, on April 9, 2009 — for it is well understood that it is generally difficult or impossible to predict the precise timing of major earthquakes — but for failing to communicate to the public the risk of a quake. The convictions of six of the seven were eventually reversed (Rosen, 2014). However, this is an area where legal precedent will likely evolve in the face of increasing climatic crisis, and the expectations that precedent places on scientists could increase as well. Of course, today's scientists will also face the judgement of history - as will those who fail to heed their warnings.

It may seem that I threaten to impose impossibly severe expectations on research scientists, whose jobs are difficult enough as it is. My aim is to point out that there does exist a 
well-established model which can provide guidance for those research scientists who do in fact feel a sense of social responsibility about the implications of their work and who are in fact troubled by the conflict that was mentioned at the beginning of this paper — that is, the conflict between the imperative to remain objective and disinterested in the conduct of scientific research, and the imperative to speak out in those cases where it would be unconscionable not to do so. Such scientists may find it comforting and steadying, in these very uncertain times, to place themselves within the long and honourable tradition of professional practice.

\section{Acknowledgments}

This paper has benefitted from commentary by or discussions with Richard Alley, Bryson Brown, William Buschert, James Byrne, Maxim Chambers-Dumont, Hector MacIntyre, Frank Jankunis, Hester Jiskoot, Dan Johnson, Stephen Latta, Stephan Lewandowsky, Pamela Lindsay, Stefan Linquist, Michael E. Mann, David McDonald, John D. Milton, Mark Musk, M.D., Dillon St. Jean, Lawrence Torcello, Grant A. Whatmough, audiences at meetings of the Canadian Philosophical Association, the Western Canadian Philosophical Association, and the 2013 Chapman Conference of the American Geophysical Union (on "Communicating Climate Science"), and anonymous referees for this journal. Financial support was provided by the University of Lethbridge, under its CREDO (Community of Research Excellence Development Opportunities), Fund 13355. It should not be presumed that any of the individuals or organizations mentioned here agree with the views expressed in this paper, and any errors or omissions are entirely the responsibility of its author. 


\section{References}

American Geophysical Union (AGU). (2013a). AGU Scientific Integrity and Professional Ethics. https://ethics.agu.org/.

American Geophysical Union (AGU). (2013b). Chapman Conference on Climate Science Communication. https://www.youtube.com/playlist?list=PL7Ihm2Mh3MZ5ZVQhhGP8pGu85dj6ued

American College of Emergency Physicians. (2008). Code of ethics for emergency physicians. http://www.acep.org/Clinical---Practice-Management/Code-of-Ethics-for-EmergencyPhysicians/.

American Medical Association (AMA). (2004). Opinion 9.07 - Medical Testimony. http://www.amaassn.org/ama/pub/physician-resources/medical-ethics/code-medical-ethics/opinion907.page .

American Society of Civil Engineers (ASCE). (2006). Code of ethics. http://www.asce.org/uploadedFiles/About_ASCE/Ethics/Content_Pieces/CodeofEthics2006.pdf .

Anderson, K. (2015). Duality in Climate Science. Nature Geoscience, 8, 898-900.

Andrews, G. C., \& Kemper, J. D. (1992). Canadian Professional Engineering: Practice and Ethics. Toronto: Saunders.

Anthony, S. (2012). CERN now 99.999999999\% sure it has found the Higgs boson ExtremeTech. http://www.extremetech.com/extreme/143497-cern-now-99-999999999-sure-it-has-found-thehiggs-boson .

Bell, E. T. (1937). Men of Mathematics. New York: Simon and Schuster.

Bennet, J., Brosz, H., Catania, J., Ellison, K., Maher, M., Porter, D., . . Veerasammy, R. (2012). Guideline for professional engineers providing forensic engineering investigations. http://www.peo.on.ca/index.php/ci_id/28085/la_id/1.htm : Professional Engineers of Ontario.

Betz, Eric. (2017). Meltdown. Discover, June 2017, 36-47.

Biddle, J. B., \& Leuschner, A. (2015). Climate skepticism and the manufacture of doubt: can dissent in science be epistemically detrimental? European Journal for Philosophy of Science, 5, 261-278. doi:10.1007/s13194-014-0101-x

Borenstein, S. (2013). What 95\% certainty means to scientists. The Big Story. Retrieved from http://bigstory.ap.org/article/what-95-certainty-warming-means-scientists

Broecker, W. S., \& Kunzig, R. (2008). Fixing Climate: What Past Climate Changes Reveal About the Current Threat--and How to Counter It. New York: Hill and Wang.

Brysse, K., Oreskes, N., O'Reilly, J., \& Oppenheimer, M. (2013). Climate Change Prediction: Erring on the Side of Least Drama? Global Environmental Change, 23(1), 327-337.

Castillo, M. (2010). The uncertainty of science and the science of uncertainty. American Journal of Neuroradiology, 31, 1767-1768. doi:10.3174/ajnr.A2106

CBC Radio (2016). Trump advisor wants to cut NASA climate change research, calls it 'politicized science'. Interview with Robert Walker on As It Happens. http://www.cbc.ca/radio/asithappens/as-it-happens-wednesday-edition-1.3864045/trump-advisorwants-to-cut-nasa-climate-change-research-calls-it-politicized-science-1.3864051

Chadwick, R. (2005). Professional Ethics and the 'good' of science. Interdisciplinary Science Reviews, $30(3), 247-256$.

Chomsky, N. (1967). The Responsibility of Intellectuals. New York Review of Books. 
DeConto, Robert M., \& Pollard, David (2016). Contribution of Antarctica to past and future sea-level rise. Nature, 531, 591. doi:10.1038/nature17145

Definition of Professional Misconduct; Ontario Regulation 538/84, Sect. 86, (1990).

Edwards, T. (2013, July 13). Climate Scientists Must Not Advocate Particular Policies, op-ed. The Guardian. Retrieved from http://www.sciencedirect.com/science/article/pii/S0959378012001215

Engineering Council, \& Royal Academy of Engineering. (2014). Statement of ethical principles for the engineering profession. http://www.engc.org.uk/engcdocuments/internet/Website/Statement\%200f\%20Ethical\%20Princip les.pdf : Engineering Council.

Favier, L., Durand, G., Cornford, S. L., Gudmundsson, G. H., Gagliardini, O., Gillet-Chaulet, F., . . Le Brocq, A. M. (2014). Retreat of Pine Island Glacier controlled by marine ice-sheet instability. Nature Climate Change, 4, 117-121. doi:10.1038/nclimate2094

Gerstein, M., \& Ellsberg, M. (2008). Flirting With Disaster: Why Accidents are Rarely Accidental. New York: Union Square Press.

Goodell, J. (2017). The Doomsday Glacier. Rolling Stone, May 9, 2017. http://www.rollingstone.com/politics/features/the-doomsday-glacier-w481260 .

Greenbaum, J. S., D.D. Blankenship, D. D., Young, D. A., Richter, T. G., Roberts, J. L., Aitken, A. R. A., ... Siegert, M. J. (2015). Ocean access to a cavity beneath Totten Glacier in East Antarctica. Nature Geoscience. doi:10.1038/ngeo2388

Hamilton, E., \& Cairns, H. (1961). The Collected Dialogues of Plato. Princeton: Princeton University Press.

Hansen, J., Sato, M., Russell, G., \& Pushker, K. (2013). Climate sensitivity, sea level and atmospheric carbon dioxide. Philosophical Transactions of the Royal Society A: Mathematical, Physical \& Engineering Sciences, 371(2001), 20120294. doi:10.1098/rsta.2012.0294

Hansen, J. E. (2007). Scientific reticence and sea level rise. Environmental Research Letters, 2, 1-6.

Hansen, J. E., Kharecha, P., Sato, M., Masson-Delmotte, V., Ackerman, F., Beerling, D. J., . . Zachos, J. C. (2013). Assessing 'Dangerous Climate Change': Required Reduction of Carbon Emissions to Protect Young People, Future Generations and Nature. PLOS One(December 3). doi:10.1371/journal.pone.0081648

Hansen, J. E., Sato, M., Hearty, P., Ruedy, R., Kelley, M., Masson-Delmotte, V., Russell, G., Tselioudis, G., Cao, J., Rignot, E., Velicogna, I., Tormey, B., Donovan, B.,Kandiano, E., von Schuckmann, K., Kharecha, P., Legrande, A.N., Bauer, M., \& Lo, K. (2016). Ice melt, sea level rise, and superstorms: evidence from paleoclimate date, climate modeling, and modern observations that $2^{\circ} \mathrm{C}$ warming could be dangerous. Atmos. Chem. Phys, 13, 3761-3812.

Harris, C. E., Jr. (1995). Explaining Disasters: The Case for Preventive Ethics. IEEE Technology and Society Magazine (Summer 1995), 76-81.

Hughes, T. (1977). West Antarctic Ice Streams. Reviews of Geophysics and Space Physics, 15(1), 1-46.

Hume, D. (1751). An Enquiry Concerning the Principles of Morals. Indianapolis: Hackett (Reprint, 1983).

International Board of Forensic Engineering Sciences (IBFES). IBFES Code of Ethics and Rules of Professional Conduct. http://www.iifes.org/ethics.htm .

IPCC. (2014). Climate Change 2014: Synthesis Report Summary for Policymakers.

https://www.ipcc.ch/index.htm . 
Jacobson, M. Z. \& Delucchi, M. L. (2011). Providing all global energy with wind, water, and solar power, Part I: Technologies, energy resources, quantities and areas of infrastructure, and materials. Energy Policy, 39, 1154-1169; doi:10.1016/j.enpol.2010.11.040.

Joughin, I., \& Alley, R. (2011). Stability of the West Antarctic ice sheet in a warming world. Nature Geoscience, 4, 506-513. doi:10.1038/ngeo1194

Joughin, I., Smith, B. E., \& Brooke, M. (2014). Marine ice sheet collapse potentially underway for the Thwaites Glacier basin, West Antarctica. Science, 344, 735-738.

Keith, D. (2013). A Case for Climate Engineering. Boston: MIT Press.

Kotcher, J.E., Myers, T.A., Vraga, E.K., Stenhouse, N., \& Maibach, E.W. (2017). Does Engagement in Advocacy Hurt the Credibility of Scientists? Results from a Randomized National Survey Experiment. Environmental Communication, 17(3), 415-429.

Lewandkowsky, S., Oreskes, N., Risbey, J. S., \& Newell, B. R. (2015). Seepage: Climate change denial and its effect on the scientific community. Global Environmental Change, 33, 1-13.

Lewandowsky, S., Risbey, J. S., Smithson, M., Newell, B. R., \& Hunter, J. (2014). Scientific uncertainty and climate change: Part I. Uncertainty and unabated emissions. Climatic Change, 124, 21-37. doi:10.1007/s10584-014-1082-7

Lindley, D. (2007). Uncertainty: Einstein, Heisenberg, Bohr, and the struggle for the soul of science. New York: Doubleday.

Mann, M. E. (2012). The Hockey Stick and the Climate Wars: Dispatches from the Front Lines. New York: Columbia University Press.

Mann, M. E., Bradley, R. S., \& Hughes, M. K. (1998). Global-scale temperature patterns and climate forcing over the past six centuries. Nature, 392, 779-787.

Mann, M. E., \& Toles, T. (2016). The Madhouse Effect: How Climate Change Denial is Threatening Our Planet, Destroying Our Politics, and Driving Us Crazy. New York: Columbia University Press.

Martin, D. (2014). Rick S. Piltz, Firebrand on Climate, Dies at 71. New York Times, Oct. 24, 2014, A25.

McKeon, R. (ed.). (1941). The Basic Works of Aristotle. New York: Random House.

Mercer, J. H. (1978). West Antarctic Ice Sheet and CO2 greenhouse effect: a threat of disaster. Nature, 271, 321-325.

Oreskes, N. (2013). The Scientist as Sentinal. Limn, 3.

Oreskes, N., \& Conway, E. M. (2010). Merchants of Doubt. New York: Bloomsbury.

Peacock, K., \& Shepherd, J. (1998). Knowledge versus opinion: Two models of professionalism. Paper presented at the The Third Annual Laurier Conference on Business and Professional Ethics, Waterloo, ON.

Pollard, D., M.DeConto, R., \& B.Alley, R. (2015). Potential Antarctic Ice Sheet retreat driven by hydrofracturing and ice cliff failure. Earth and Planetary Science Letters, 412, 112-121. doi:10.1016/j.eps12014.12.035

Poortinga, W., Spence, A., Whitmarsh, L., Capstick, S., \& Pidgeon, N.F. (2011). Uncertain climate: An investigation into public scepticism about anthropogenic climate change. Global Environmental Change, 21, 1015-1025. doi:10.1016/j.gloenvcha.2011.03.001

Powell, J. L. (2011). The Inquisition of Climate Science. New York: Columbia University Press. Professional Engineers of Ontario (PEO) (2010). A Professional Engineer's Duty to Report: Professional Engineers of Ontario. 
Rahmstorf, S. (2013). Sea-level rise: Where we stand at the start of 2013. Retrieved from http://www.realclimate.org/index.php/archives/2013/01/sea-level-rise-where-we-stand-at-thestart-of-2013/

Rignot, E. (2014). Widespread, rapid grounding line retreat of Pine Island, Thwaites, Smith, and Kohler glaciers, West Antarctica, from 1992 to 2011. Geophysical Research Letters, 41(10), 3502-3509. doi:10.1002/2014g1060140

Rignot, E. (2015). Interview. https://www.youtube.com/watch?v=0nOZwCitHgg

Risbey, J. S. (2008). The new climate discourse: Alarmist or alarming? Global Environmental Change, $18,26-37$.

Ropeik, D. (2012, October 22). The L'Aquila Verdict: A Judgment Not against Science, but against a Failure of Science Communication. Retrieved from http://blogs.scientificamerican.com/guestblog/the-laquila-verdict-a-judgment-not-against-science-but-against-a-failure-of-sciencecommunication/

Rosen, J. (2014). Six of the L'Aquila Seven Acquitted in Appeal. Eos, 95(46), 418.

Russell, B. \& Einstein, A. (1955). The Russell-Einstein Manifesto. https://pugwash.org/1955/07/09/statement-manifesto/

Schindler, D. (2017). Facts Don’t Matter. Alberta Views, July/August 2017, 36-40.

Schmidt, Gavin. (2013). AGU Chapman Conference on Climate Science Communication. http://www.realclimate.org/index.php/archives/2013/07/agu-chapman-conference-on-climatescience-communication/

Schneider, S. H. (1988). The greenhouse effect and the U.S. summer of 1988: Cause and effect or a media event? Climatic Change, 13, 113-115.

Shrader-Frechette, K. (1986). The Conceptual Risks of Risk Assessment. IEEE Technology and Society Magazine, 5(2); reprinted in Flores, A. (ed.), Ethics and Risk Management in Engineering. New York, Lantham, 1989, pp. 73-90.

Smolin, L. (2006). The Trouble With Physics: The rise of String Theory, the fall of a science, and what comes next. Boston \& New York: Houghton Mifflin.

Taleb, N. N. (2010). The Black Swan: The impact of the highly improbable (2nd ed.). New York: Random House.

Torcello, L. (2011). The Ethics of Inquiry, Scientific Belief, and Public Discourse. Public Affairs Quarterly, 25(3), 197-215.

Torcello, L. (2014, 13 March 2014). Is misinformation about the climate criminally negligent? Retrieved from http://blogs.scientificamerican.com/guest-blog/the-laquila-verdict-a-judgment-not-againstscience-but-against-a-failure-of-science-communication/

Torcello, L. (2017). Yes, I am a climate alarmist. The Guardian, 27 April, 2017. https://www.theguardian.com/commentisfree/2017/apr/29/climate-alarmist-global-warmingcrime-humanity

UNFCCC (United Nations Framework Convention on Climate Change). (2015). Text of Paris Agreement. http://unfccc.int/resource/docs/2015/cop21/eng/109r01.pdf

Vaughn, D. G., \& Arthern, R. (2007). Why Is It Hard to Predict the Future of Ice Sheets? Science, 315, 1503-1504. doi:10.1126/science.1141111

Weart, S. (2014). The Discovery of Global Warming. American Institute of Physics. https://www.aip.org/history/climate/index.htm 
Weertman, J. (1974). Stability of the junction of an ice sheet and an ice shelf. Journal of Glaciology, 13, 3-11.

World Bank (2007). The Impact of Sea Level Rise on Developing Countries: A Comparative Analysis. http://documents.worldbank.org/curated/en/156401468136816684/pdf/wps4136.pdf 